\title{
Measuring Specific Purpose Orientations in Working Adults
}

\author{
Mariya A. Yukhymenko-Lescroart ${ }^{1} \mathbb{D} \cdot$ Gitima Sharma $^{2} \mathbb{D}$ \\ Received: 25 July 2021 / Accepted: 22 August 2021 /Published online: 2 September 2021 \\ (C) The International Society for Quality-of-Life Studies (ISQOLS) and Springer Nature B.V. 2021
}

\begin{abstract}
The purpose of this study was to develop and validate a scale designed to measure specific purpose orientations among adults. Following literature review, a pool of items was developed and pilot tested with a convenience sample of adults recruited through MTurk $(N=554)$. Exploratory factor analysis suggested three distinct dimensions of others-growth, self-growth, and career-focused purpose orientations. The three-factor structure was confirmed with two independent samples of intercollegiate coaches in Study $2(N=377)$ and with teachers in Study $3(N=247)$ through the use of confirmatory factor analysis. Construct validity of the items was assessed, which included examining factor loadings and reliability, convergent validity, discriminant validity, and nomological validity. Overall, the 12 items measuring purpose orientations are suggested as valid and reliable for research and for reflection on the nature of their life purpose to ultimately promote wellbeing in adult populations.
\end{abstract}

Keywords Purpose $\cdot$ Purpose orientation $\cdot$ Work $\cdot$ Life goals $\cdot$ Motivation $\cdot$ Adults

Purpose is recognized as one of the most important assets for maintaining health and wellness over the life span (Windsor et al., 2015). Research has consistently demonstrated purpose as a significant contributor for people's wellbeing, positive affect, good health, hope, happiness, persistence, motivation, career success (e.g., Bronk et al., 2009; Burrow \& Hill, 2011; Hill et al., 2018; Kang et al., 2019; Kim et al., 2020; Sharma \& de Alba, 2018; Windsor et al., 2015; Yeager \& Bundick, 2009). Scholars have also emphasized that people who are aware of and find purpose in professional and personal roles are most equipped to cope with stress caused by role conflicts and enjoy a sense of work-life balance (e.g., Bragger et al., 2021). For example, Bragger et al. (2021) found that couples who share a sense of purpose in

Mariya A. Yukhymenko-Lescroart

mariyay@mail.fresnostate.edu

1 Department of Curriculum and Instruction, California State University, Fresno, 5005 N. Maple Ave., M/S ED 2, Fresno, CA 93740, USA

2 Department of Counselor Education and Rehabilitation, California State University, Fresno, Fresno, CA, USA 
their careers experience lesser work-family strain-based conflict and greater benefits in their family lives. Graça et al. (2021) reported that when working adults such as higher education teachers and researchers recognize their work's value in contributing to the betterment of society, they experience greater sense of motivation, happiness, and productivity. Therefore, helping working adults connect meaning at work with their life's larger purpose can contribute to their positive work outcomes, relationships, and personal wellbeing (Bragger et al., 2021; Graça et al., 2021).

Given the important role of purpose in various aspects of people's lives, multiple measures of purpose have been developed (e.g., Crumbaugh \& Maholick, 1964; Ryff, 1989). However, most of these measures have focused only on assessing the extent to which people are aware of their purpose in life instead of the nature of their life's purpose. Literature has shown that in addition to a general sense of purpose, specific purpose orientations play a critical role in impacting people's wellness and career outcomes (e.g., Hill et al., 2010; Sharma et al., 2017, 2021). For example, Hill et al. (2010) demonstrated that during middle adulthood, prosocial purpose orientation is more predictive of greater generativity, personal growth, and integrity in contrast to other purpose orientations. Likewise, Sharma and Yukhymenko-Lescroart (2018) found a positive relationship between college students' altruistic purpose in life and degree commitment. Sharma et al. (2017) however found that students with career purpose orientation were more likely to enroll in college. Sharma et al. (2021) further reported that among four types of purpose (career, interpersonal, altruistic, and self-oriented), career and interpersonal purpose orientations were positively related to college students' postsecondary completion. Developing an instrument that can assess people's purpose orientations could further advance clarity about the nature and role of purpose orientations among people from different cultural and age groups, and promote purpose-fostering interventions (Wang et al., 2020) .

The present study focuses on the development and validation of the purpose orientation scale in adults to assess their occupational well-being. The pursuit of this study is a timely endeavor due to the challenges posed by COVID-19 pandemic and the resulting economic downturn, which has not only caused financial stress among innumerable working-adults but also a loss of purpose that often arises from careerfocused efforts. Several existential and humanistic scholars have indeed stressed that it is during the most challenging times of transitions that people often seek to explore, clarify, and develop purpose (Dalton \& Crosby, 2010; Frankl, 1984; Ikeda, 2017). Therefore, the scale can be used for research and for reflective purposes to help in actualizing the vision of transforming current times of adversity into periods of reflection and growth.

\section{Defining and Assessing Purpose Orientations}

Hill et al. (2010) defined purpose orientations as the "constellations of related, longterm life goals" (p. 174). According to Hill et al. (2010), purpose in life is indicated by people's multiple and often related life goals instead of a single goal. To give an example, Hill et al. (2010) expressed that people with an altruistic purpose might have several altruistic life goals such as serving their community, helping others, 
influencing the social structure and so forth, instead of only one prosocial goal. Hill et al. (2010) further conducted factor analysis on 17 different life-goals listed in the UCLA's Higher Education Research Institute's (HERI) survey and identified four purpose orientations among college students: prosocial, financial, creative, and personal recognition orientations. Based on Hill et al.'s (2010) conceptualization, Sharma et al. (2017) conducted factor analysis on the 14 life-goals included in the Educational Longitudinal Study 2002 (ELS:2002) database and reported four purpose orientations among high school students: career, interpersonal, altruistic, and self-oriented orientations. One of the limitations of Hill et al.'s (2010) and Sharma et al.'s (2017) research is that their assessment of purpose orientations was limited to pre-developed surveys. Sharma et al. (2017) indeed reported that due to the limited items in ELS:2002 database and low reliabilities of the self-oriented and altruistic purpose orientations, the results of their study might not have fully captured the essence and role of these two purpose orientations.

Another study that has focused on the construct of life's major goals was conducted by Roberts and Robbins (2000). Major life goals refer to people's aspirations to shape their life context and construct general life structures such as having a family, a certain lifestyle, a career, and so forth (Roberts \& Robbins, 2000). Based on theoretical and empirical procedures to organize a set of life goals into thematic content clusters, Roberts and Robbins (2000) revealed the following major goal clusters: economic, aesthetic, social, relationship, political, hedonistic, and religious. Yet, while purpose and life goals are related constructs, they are also distinct. One main distinction is that purpose is a generalized intention behind people's far-reaching goals (Damon et al., 2003) and a source of inspiration to fulfill current goals (McKnight \& Kashdan, 2009). Yeager and Bundick (2009) investigated the relationship between work goals, purpose, and meaning among adolescents. Based on a mixed-methods study, Yeager and Bundick (2009) reported four types of reasons behind adolescents' work-related goals: intrinsic self-oriented reasons, intrinsic beyond-the-self-oriented reasons, extrinsic self-oriented reasons, and extrinsic beyond-the-self-oriented reasons. Recently, informed by Yeager and Bundick's (2009) findings, Summers and Falco (2020) assessed adolescents' orientations for purpose, which they described as primary reason or motivation for fulfilling their life's goal. To evaluate orientations for purpose, Summers and Falco (2020, p. 70) created a single item seeking adolescents' selection of one of the following primary reasons to pursue their life's goal: (a) "It is interesting to me; I think I will be good at it [Intrinsic/Self-Oriented]"; (b) "I want to help others and make the world a better place [Intrinsic/Other-Oriented]"; (c) "I want to have a secure job/comfortable income [Extrinsic; Self-Oriented]"; and (d) "I want to make a positive contribution to my community and/or society [Extrinsic; Other-Oriented]." While not variable-centered, Heng et al. $(2017,2020)$ performed cluster analysis of life goals among Singapore and Israel adolescents, yielding the following purpose clusters of youth: (a) self- and other focused; (b) self-focused; (c) other-focused; and (d) no orientation or no discernible life purpose. Most recently, Wang et al. (2020) developed a Chinese life purpose orientation questionnaire to help cultivate and assess different domains of life purpose among Chinese college students. Wang et al. (2020) questionnaire has 18 items encompassing five domains of purpose: pleasure seeking, self-strengthening, family harmony, social recognition, and social dedication. One of the limitations of Wang et al. (2020) 
questionnaire as they acknowledged is that their items "appear as measures of values for some dimensions" (p. 11).

All of the above-mentioned studies (Hill et al., 2010; Sharma et al., 2017; Summers \& Falco, 2020; Yeager \& Bundick, 2009; Wang et al., 2020) have been conducted for school and college youth. A measure of purpose that has been validated across diverse age groups, including with working adults, is the Revised Sense of Purpose Scale (SOPS-2; Sharma \& Yukhymenko-Lescroart, 2019; YukhymenkoLescroart \& Sharma, 2020a, b). However, apart from altruistic purpose, defined as people's aspiration to make a positive difference in society, this scale does not assess other purpose orientations.

\section{Purpose of the Study}

In sum, there have been fewer attempts to assess people's purpose orientations in contrast to their generalized sense of purpose (Hill et al., 2010; Wang et al., 2020). Despite the important contributions of the few studies on the nature of purpose, the current assessments of purpose orientations have significant limitations such as being: (a) based on pre-existing surveys on life goals that were not revised or expanded upon (e.g., Hill et al., 2010); (b) primarily focused on altruistic nature of purpose (e.g., Yukhymenko-Lescroart \& Sharma, 2020a, b); (c) confounded with other constructs such as life values (e.g., Wang et al., 2020); and (d) primarily developed for school and college youth (e.g., Summers \& Falco, 2020).

Given, these limitations, the aim of the present study was to develop and validate a scale that measures specific purpose orientations in working adults. Within the present study, the aim of Study 1 was to develop and pilot test a set of items designed to measure purpose orientations in adults in order to determine the number of latent variables that underline the items, examine their factorial structure, and select best performing items. The aim of Study 2 was to test the factorial structure identified in Study 1 with an independent sample, to further refine the scale, and to optimize its length. The final items were then tested in Study 3 with a new independent sample to confirm the factor structure. The goals of Studies 2 and 3 also included assessing construct validity of the items, which included factor loadings and reliability, convergent validity, discriminant validity, and nomological validity. Overall, the scale development process was guided by the guidelines proposed by DeVellis (2017). In Study 1, we used a convenience sample of adults recruited through MTurk website. In Studies 2 and 3, we used samples of intercollegiate coaches (Study 2) and K-12 teachers (Study 3).

\section{Method}

\section{Procedure and Participants}

In Study 1, participants were recruited in July 2019 through the MTurk website (www.MTurk.com), which has been shown to produce reliable data (Buhrmester 
et al., 2018). The inclusion criteria were that participants had to be located in the United States, have English as their first language, be at least 18 years old, and agree to participate by rating their agreement or disagreement with the items and providing responses to a brief demographic section. Participants were 554 adults, aged between 20 and 81 years $(M=43.4, M d n=42.0, S D=12.8)$. Among them, $30.9 \%$ were men, $60.1 \%$ were women, and $9.0 \%$ did not report their gender. Participants were able to select multiple race/ethnic categories and self-identified as follows: American Indian or Alaska Native $(n=5)$, Asian $(n=38)$, Black or African American $(n=37)$, Hispanic or Latinx $(n=32)$, Native Hawaiian or Pacific Islander $(n=1)$, White $(n=411)$, and "Other" $(n=4)$. As well, 51.4\% reported having children, $39.4 \%$ reported not having children, and $9.2 \%$ did not respond to this question. At the time of data collection, $60.5 \%$ of participants were employed full-time and $16.2 \%$ were employed part-time, representing a variety of professions, $14.1 \%$ were not employed, and 9.2\% did not answer to this question. All of the participants were MTurk "workers," who were paid to participate in the survey, and everyone who met the inclusion criteria and responded correctly to one validation question (i.e., "Please select "agree" for this question), were retained for the data analysis phase.

In Study 2, we recruited intercollegiate coaches from a number of different states by sending them emails with the link to the survey during the last week of August 2020 with one reminder that was sent two weeks later. We received responses from 377 coaches, $62.5 \%$ men and $37.4 \%$ women, from Division I $(n=144)$ and III $(n=233)$. Coaches were asked to indicate an age category, and 84 reported that they were between 18-29 years, 145 were between 30-44 years, 129 were between 45-64, 18 were 65 or older, and one coach did not select an age category. Similarly to Study 1, participants were able to select multiple race/ethnic categories and self-identified as follows: American Indian or Alaska Native $(n=1)$, Asian $(n=11)$, Black or African American $(n=24)$, Hispanic or Latinx $(n=12)$, Native Hawaiian or Pacific Islander $(n=1)$, White $(n=331)$, and "Other" $(n=5)$. These sample included head coaches $(54.6 \%)$, associate coaches (7.4\%), and assistant coaches (34.7\%), who represented a variety of sports, and the vast majority were full-time coaches $(92.8 \%)$. They reported to have been coaching between 1 and 55 years $(M=17.8, M d n=16.0, S D=11.7)$. At the time of data collection, coaches were pre-season (49.3\%), in season (13.8\%), and off season $(36.3 \%)$; and two coaches $(0.5 \%)$ did not report the sport season status for their sport.

In Study 3, we recruited K-12 teachers who worked in various schools in California by sending them an email with an invitation to complete the survey in November 2020 with two reminders. Participants were 247 teachers who reported teaching at the elementary $(n=54)$, middle $(n=56)$, and high school $(n=136)$ levels. Participants came from a total of 186 schools. The majority of teachers described their schools as suburban $(n=147)$, followed by rural $(n=47)$, urban $(n=39)$, or a combination $(n=11)$, or a charter $(n=3)$. Teachers reported teaching between 1 and 46 years $\left(M=22.9\right.$ years, $M_{d n}=23$ years, $\left.\mathrm{SD}=8.5\right)$. Most teachers reported that this was their first career $(70.9 \%)$. 


\section{Measures}

\section{Specific Purpose Orientations}

The final set included 29 items that were developed to measure purpose orientation of working adults. The development of these items was based on the review of studies as outlined in the literature review as well as inspired by reviewing the 712 quotes about purpose of life posted on the Goodreads (n.d.) website. Specifically, we aimed to develop items that would assess several orientations of life purpose, which we hypothesized to represent five dimensions. The first dimension was focused on helping others grow (e.g., "To make people aware that they can accomplish more, aim higher, and reach for excellence") and consisted of eight items. We also added a dimension titled altruistic: community-oriented (e.g., "To make a positive difference in my community"), which consisted of five items, all of them were rephrased from the altruistic purpose subscale of the Sense of Purpose Scale (Sharma \& Yukhymenko-Lescroart, 2018). The third dimension was focused on nurturing personal virtues (e.g., "To cultivate compassion and empathy within me") and consisted of five items. The fourth dimension was focused on personal growth (e.g., "To aim higher and reach for excellence") and consisted of eight items. Finally, the fifth dimension was career-focused purpose orientation (e.g., "To be successful in the field of my work") and consisted of three items. Prior to finalization of the set, items were sent for content validation feedback (DeVellis, 2017) for relevance and clarity and received suggestions were carefully considered. These items were then pilottested with the following instructions: "Please read each statement below and indicate how much you agree or disagree with each of them. There are no right or wrong answers. Please be open and honest in your responding." The items had a common stem, "My purpose in life is...," followed by the list of items and a 7-point response scale, ranging from $1=$ strongly disagree to $7=$ strongly agree .

\section{Sense of Purpose}

In addition to items measuring purpose orientations, in each of the three studies, we also administered the Revised Sense of Purpose Scale (SOPS-2, YukhymenkoLescroart \& Sharma, 2020a, b), which consists of three subscales: awakening to purpose (four items), awareness of purpose (five items), and altruistic purpose (five items). We were especially interested in the altruistic purpose subscale, because it can be considered as a type of purpose orientation. Therefore, we were interested in examining how our new items perform in relation to the SOPS-2 items. We chose the SOPS-2, because psychometric properties of the SOPS-2 items have been rigorously examined with, showing strong evidence of reliability and validity in a series of validation and application studies with college students and adults (e.g., Sharma \& Yukhymenko-Lescroart, 2019; Yukhymenko-Lescroart \& Sharma, 2020a, b). The instructions for these items were the same as for the new items, and items were accompanied with a 7 -point response scale, ranging from $1=$ strongly disagree to $7=$ strongly agree. 


\section{Data Analysis}

Analyses in Study 1 were focused on determining how many latent variables underlined the set of the developed items and selecting best performing items. First, parallel analysis, which was found to be accurate across a wide range of situations (Hair et al., 2019), was used to decide on the number of factors, by using an SPSS macro (O'Connor, 2000). Then, exploratory factor analysis was performed with principal axis factoring extraction to consider the shared variance among items and with direct Oblimin rotation, which allows correlated factors (Hair et al., 2019). The results were examined for the amount of variance explained by each factor and factor loadings. Following Hair et al. (2019) guidelines, it was expected that each factor would account for at least $5 \%$ of the variance, and that factor loadings would be at last $1.50 \mathrm{I}$, which would signal considered practical significance, with loadings exceeding $1.70 \mathrm{l}$ indicating well-defined factor structure. In addition to statistical considerations, items were also examined based on conceptual considerations in order to optimize scale length. Generally shorter scales are good because they provide less burden on participants; thus, length optimization of a scale is an important consideration in a scale development and validation process (DeVellis, 2017). In the next step, the factors were labeled and interpreted. Next, internal consistency of items within each factor was examined based on the values of Cronbach's alpha, after which mean scores were computed for each dimension and examined using descriptive statistics. Bivariate correlations were examined among the items of purpose orientations and with the three dimensions of the sense of purpose (i.e., awakening to purpose, awareness of purpose, and altruistic purpose). Finally, the subscale scores were compared across employment status and parenthood status to examine nomological validity (Hair et al., 2019) of scores.

The main analysis in Studies 2 and 3 was confirmatory factor analysis (CFA), which was used to test the factorial structure identified in Study 1. CFA models were tested in Mplus, version 8.5 (Muthén \& Muthén, 2012-2021) using maximum likelihood estimation method with robust standard errors. Models were assessed based on several fit indices, following Hair et al.'s (2019) guidelines for models with 12 to 30 observed variables and samples sizes of over 250, which suggest that Comparative Fit Index (CFI) and Tucker-Lewis Index (TLI) of above 0.94, Root Mean Squared Error of Approximation (RMSEA) of less than 0.07, and Standardized Root Mean Square Residual (SRMR) of 0.08 or less would provide evidence of relatively good fit. In Study 2, we also used CFA to further refine the scale, select best-performing items, and optimize scale length (DeVellis, 2017), which was then also tested in Study 3. Once the final model was accepted, we then examined construct validity in Studies 2 and 3, which included factor loadings and reliability, convergent validity, discriminant validity, and nomological validity, following guidelines of Hair et al. (2019). Specifically, factor loadings would be above 0.50 , preferably above 0.70 , would indicate high convergent validity, or that the items share a high proportion of variance in common. Reliability, which is also an indicator of convergent validity, was examined based on construct reliability (CR), which is often used in conjunction with CFA models instead of coefficient alpha. CR values above 0.70 would indicate that internal consistency exists with all items consistently representing the 
same latent construct. For additional evidence of adequate convergence, the average variance extracted (AVE) values would be above 0.50 , but below the corresponding values of $\mathrm{CR}$. For evidence of discriminant validity, which means that individual measured items represent only one latent construct, we expected that AVE values for each subscale would be greater than the corresponding values of average shared variance (ASV) and maximum shared variance (MSV). Finally, for evidence of nomological validity, which is tested by examining whether the correlations among the constructs in a measurement theory make sense (Hair et al., 2019, p. 677), we expected that the purpose orientation subscales would be positively associated with the subscales of altruistic purpose, awareness of purpose, and awakening to purpose. In addition to using the SOPS-2 items, nomological validity was also assessed based on several classification variables (Hair et al., 2019, p. 690), including years that the participants had worked in their fields in Studies 2 and 3, as well as coaches' sex (male, female), level of athletics (Division I, Division III), and where coaches were in their season (pre-season, in season, off season) in Study 2 and teachers' grade level (elementary, middle, high school), the type of school (urban, suburban, rural), and whether teaching was their first career (yes, no) in Study 3.

\section{Study 1 Results}

There were no missing data on the individual items. The parallel analysis, which was used to decide on the number of factors to extract, suggested three factors. Therefore, three factors were specified in the exploratory factor analysis. Overall, the solution was generally satisfactory, with only one item that had high loading on the secondary factor and one item that did not have high loading on the primary factor. These two items, which were originally developed for the self-growth subscale, were removed for statistical reasons. Next, items were closely examined for conceptual sense, with two more items being removed from the self-growth subscale and eight items being removed from the others-grow subscale. Exploratory factor analysis was re-run with the remaining 17 items. Results showed that a total of $73.2 \%$ of the variance was explained by the item. The first factor, which consisted of seven self-growth orientation items, explained $55.2 \%$ of the variance, with factor loadings for these items ranging from 0.69 to 0.90 . The second factor, which consisted of seven others-growth orientation items, explained $11.4 \%$ of the variance, with factor loadings ranging from 0.81 to 0.90 . The third factor, which consisted of three work-oriented items, explained $6.7 \%$ of the variance, with factor loadings ranging from 0.81 to 0.93 . Cronbach's alphas were computed for each subscale, showing that Cronbach's alphas were 0.93 for the self-growth purpose orientation subscale (interitem correlations: $M=0.67, S D=0.05), 0.96$ for the others-growth purpose orientation subscale (inter-item correlations: $M=0.76, S D=0.04$ ), and 0.92 for the careerfocused purpose orientation subscale (inter-item correlations: $M=0.78, S D=0.01$ ).

Mean scores were computed for the subscales to examine descriptive statistics and Pearson's correlations (see Table 1). Mean scores suggested that adults in this sample reported the highest scores on self-growth purpose orientation, followed by work-oriented purpose orientation and others-growth purpose orientation. The three 
subscales were moderately and positively correlated, with Pearson's correlations ranging from 0.53 to 0.60 . Additionally, all three purpose orientation subscales were positively correlated with the three subscales of the SOPS-2. As expected, the highest correlation was between others-growth purpose orientation and altruistic purpose, $r(552)=0.74, p<0.001$. Overall, the SOPS-2 subscales had the strongest correlations with the others-growth purpose orientation subscale ( $r$ ranged from 0.51 to 0.74 ), and the weakest correlations with the career-focused purpose orientation subscale ( $r$ ranged from 0.32 to 0.42 ).

Mean differences were examined across employment status and parenthood status on the three subscales. Differences emerged across employment status for careerfocused purpose orientation only, $F(2,500)=6.19, p=0.002, \eta^{2}=0.024$. The post hoc multiple comparison tests with Bonferroni correlation showed that unemployed adults $(M=4.77, S D=1.34)$ reported significantly lower work-oriented purpose orientation than full-time $(M=5.35, S D=1.33, p=0.002)$ and part-time working adult $(M=5.29, S D=1.06, p=0.031)$. But no differences emerged between fulltime and part-time adults on work-oriented purpose orientation. Finally, differences emerged across parenthood status on others-growth and self-growth purpose orientation subscales. Compared to adults without children, adults with children reported higher others-growth purpose orientation, $\left(F(1,501)=6.21, p=0.013, \eta^{2}=0.012\right.$, $M=5.02, S D=1.28$ vs. $M=4.71, S D=1.44)$, and a slightly higher self-growth purpose orientation $\left(F(1,501)=4.21, p=0.041, \eta^{2}=0.006, M=5.80, S D=0.87\right.$ vs. $M=5.62, S D=1.05)$.

\section{Study 1 Discussion}

Following the literature review, an initial item pool was generated, examined for content validity, and submitted for pilot-testing with a sample of 554 adults. As a result of exploratory factor analysis, 17 items were selected, which showed a reasonable three-factor structure based on several diagnostics, including variance explained, factor loadings, Cronbach's reliabilities, descriptive statistics, and Pearson's correlations. These items were retained for testing in Study 2, but several modifications

Table 1 Reliability, Descriptive, and Correlation Statistics in Study 1, N=554

\begin{tabular}{lllllll}
\hline & & & \multicolumn{4}{c}{ Correlations } \\
\cline { 5 - 7 } Subscale & Cronbach's $a$ & $M$ & $S D$ & 1 & 2 & 3 \\
\hline 1. Others-Growth Purpose Orientation & .96 & 4.89 & 1.35 & - & & \\
2. Self-Growth Purpose Orientation & .93 & 5.67 & 0.99 & $.60^{* * *}$ & - & \\
3. Career-Focused Purpose Orientation & .92 & 5.23 & 1.33 & $.53^{* * *}$ & $.59^{* * *}$ & - \\
4. Awakening to Purpose & .95 & 4.60 & 1.51 & $.56^{* * *}$ & $.46^{* * *}$ & $.39^{* * *}$ \\
5. Awareness of Purpose & .98 & 4.52 & 1.68 & $.51^{* * *}$ & $.38^{* * *}$ & $.32^{* * *}$ \\
6. Altruistic Purpose & .93 & 5.29 & 1.16 & $.74^{* * *}$ & $.53^{* * *}$ & $.42^{* * *}$ \\
\hline
\end{tabular}

Note. ${ }^{* * *} p<.001$ 
were implemented. First, an others-growth purpose orientation item "To spend my life making a positive impact on others" was simplified by modifying it into "To make a positive impact on others." Second, an others-growth purpose orientation item "To help others achieve their goals (or enjoy their lives)" was split into two items: "To help others achieve their goals" and "To help others enjoy their lives." Third, because one of the removed items "To reach for excellence" cross-loaded on both self-growth and career-focused purpose orientation factors, it was revised and added to the career-focused purpose orientation subscale, "To reach for excellence in my work." These modifications resulted in a set of 20 items, which were tested in Study 2 with an independent sample of working adults, specifically intercollegiate coaches. The 20 items included nine others-growth purpose orientation items, seven self-growth purpose orientation items, and four career-focused purpose orientation items and used the 1 (strongly disagree) to 7 (strongly agree) response scale. The purpose of Study 2 was to confirm factor structure identified in Study 1 by using confirmatory factor analysis, and to further refine the scale by optimizing its length with an independent sample of working adults.

\section{Study 2 Results}

No missing data were observed on the individual items. The nine items of othersgrowth purpose orientation, the seven items of self-growth purpose orientation, and the four items of career-focused purpose orientation were specified as indicators of their hypothesized factors in a confirmatory factor analysis model. This 20-item model showed a poor fit: $\chi^{2}(167, N=377)=539.2, p<0.001, \mathrm{CFI}=0.883$, $\mathrm{TLI}=0.867, \mathrm{RMSEA}=0.077,90 \%$ CI $[0.070,0.084]$, SRMR $=0.053$. Examination of factor loadings, standardized residuals, and modification indices pointed to five items of the others-growth purpose orientation subscale and three items of the selfgrowth purpose orientation that were subjected for removal. The fit of the model with the remaining 12 items, specifically, four items per subscale, showed an acceptable model fit (MLR): $\chi^{2}(51, N=377)=139.2, p<0.001$, CFI $=0.948$, TLI $=0.932$, RMSEA $=0.068,90 \%$ CI $[0.054,0.081]$, SRMR $=0.050$. Factor loadings, which are shown in Table 2, were significant and ranged from 0.69 to 0.83 .

As shown in Table 3 , construct reliability estimates were 0.85 for others-growth, 0.84 for self-growth, and 0.87 for career-focused purpose orientation and were all above 0.70 . Convergent validity was suggested by the AVE values, which were 0.59 for others-growth, 0.57 for self-growth, and 0.62 for career-focused purpose orientation and were all greater 0.50 but less than the corresponding CR values. Discriminant validity was suggested by the ASV and MSV values, which were 0.42 and 0.45 for others-growth, 0.40 and 0.45 for self-growth, and 0.37 and 0.38 for careerfocused purpose orientation and were all lower than their corresponding AVE values (Table 3).

Next, correlations were examined with the SOS-2 items. The combined model with six factors showed a good model fit: $\chi^{2}(284, N=377)=551.0, p<0.001$, $\mathrm{CFI}=0.949, \mathrm{TLI}=0.941, \mathrm{RMSEA}=0.050,90 \%$ CI $[0.044,0.056], \mathrm{SRMR}=0.045$. As shown in Table 3, all three purpose-orientation factors were positively correlated 
Table 2 Standardized Factor Loadings for Items of Purpose Orientation Working Adults Scale in Studies 2 and 3

\begin{tabular}{lll}
\hline Items & $\begin{array}{l}\text { Study 2, } \\
N=377\end{array}$ & $\begin{array}{l}\text { Study 3, } \\
N=247\end{array}$ \\
\hline Others-Growth & & .79 \\
1. To make a positive impact on others & .82 & .83 \\
2. To promote people's wellbeing & .82 & .86 \\
3. To make people aware that they can accomplish more, aim higher, and & .69 & \\
reach for excellence & & .87 \\
4. To enrich the experience of the lives of people & .76 & .81 \\
Self-Growth & & .82 \\
5. To actualize myself in one or many areas & .72 & .87 \\
6. To inspire myself to be courageous and push aside the inner doubts & .73 & .83 \\
7. To enjoy and savor life as best as I can & .80 & \\
8. To develop a healthy and happy lifestyle & .77 & .90 \\
Career-Focused & & .87 \\
9. To be successful in the field of my work & .83 & .87 \\
10. To be an expert in the field of my work & .77 & .83 \\
11. To be an example for other people in my field of work & .76 & .80 \\
12. To reach for excellence in my work & &
\end{tabular}

Table 3 Validity Information: Reliability and Variance Explained

\begin{tabular}{lllll}
\hline & CR (Cronbach's a) & AVE & ASV & MSV \\
\hline Study 2, $N=377$ & & & & \\
1. Others-growth purpose orientation & $.85(.85)$ & .59 & .42 & .45 \\
2. Self-growth purpose orientation & $.84(.84)$ & .57 & .40 & .45 \\
3. Work-focused purpose orientation & $.87(.86)$ & .62 & .38 & .37 \\
Study 3, $N=247$ & & & .63 & .35 \\
1. Others-growth purpose orientation & $.87(.90)$ & .63 & .34 & .32 \\
2. Self-growth purpose orientation & $.87(.90)$ & .65 & .35 & .35 \\
3. Work-focused purpose orientation & $.88(.92)$ & & \\
\hline
\end{tabular}

Note. $\mathrm{CR}=$ construct reliability, $\mathrm{AVE}=$ average variance extracted, $\mathrm{ASV}=$ average shared variance, $\mathrm{MSV}=$ maximum shared variance

with the SOPS-2 subscales of awakening to purpose, awareness of purpose, and altruistic purpose, with correlations ranging from 0.33 to $0.74, p<0.001$. As expected, the highest correlation was between others-growth and altruistic purpose, $r(245)=0.74, p<001$. All other correlations were moderate in magnitude. Overall, these results provided evidence of criterion validity.

Means and standard deviations for the three purpose-orientation dimensions are shown in Table 4. Tests of within-subject effects comparing strength of the three purpose orientations emerged significant, $F(2,752)=32.06, p<0.001, \eta_{\text {partial }}^{2}=$ 
0.08, suggesting that coaches reported higher scores on some dimensions of purpose orientation relatively to the other dimensions. Tests of within-subject simple contrasts showed that compared to self-growth oriented purpose $(M=5.95, S D=0.82)$, coaches reported much stronger others-growth oriented purpose $(M=6.21$, $\left.S D=0.71, F(1,376)=54.43, p<0.001, \eta_{\text {partial }}^{2}=0.13\right)$ and career-focused oriented purpose $\left(M=6.20, S D=0.75, F(1,376)=39.91, p<0.001, \eta_{\text {partial }}^{2}=0.10\right)$. However, no differences emerged in the strength of others-growth and career-focused purpose orientation $(F(1,376)=0.21, p=0.646)$.

There was a small significant correlation between the years of coaching and career-focused purpose orientation $(r(375)=0.130, p=0.011)$, suggesting that the longer coaches have been coaching, the higher they reported their career-focused purpose orientation. However, no differences in others-growth, self-growth, and career-focused purpose orientation was found based on coaches' gender (male, female), Division (I, III), and where they were in season (pre-season, in season, off season).

\section{Study 2 Discussion}

Results from CFA confirmed the three factors of purpose orientation with focus on self-growth, others-growth, and work. Initial evidence of construct validity and reliability was shown. However, when CFA results suggest more than minor modifications, such as deleting a large number of items, the results of the CFA should be re-evaluated with a new dataset (DeVellis, 2017). In Study 3, we assessed the

Table 4 Descriptive and Correlation Estimates in Studies 2 and 3

\begin{tabular}{|c|c|c|c|c|c|}
\hline \multirow[b]{2}{*}{ Subscale } & \multirow[b]{2}{*}{$M$} & \multirow[b]{2}{*}{$S D$} & \multicolumn{3}{|l|}{ Correlations } \\
\hline & & & Others-Growth & Self-Growth & Career-Focused \\
\hline \multicolumn{6}{|l|}{ Study $2, N=377$} \\
\hline 1. Others-growth purpose orientation & 6.21 & 0.71 & - & & \\
\hline 2. Self-growth purpose orientation & 5.95 & 0.82 & $.67^{* * * *}[.55, .80]$ & - & \\
\hline 3. Career-focused purpose orientation & 6.20 & 0.75 & $.62^{* * *}[.45, .78]$ & $.60^{* * *}[.45, .74]$ & - \\
\hline 4. Awakening to purpose & 5.22 & 1.18 & $.50^{* * *}[.41, .60]$ & $.47^{* * *}[.36, .58]$ & $.36^{* * *}[.26, .46]$ \\
\hline 5. Awareness of purpose & 5.18 & 1.38 & $.43^{* * * *}[.31, .55]$ & $.39^{* * * *}[.27, .50]$ & $.33^{* * * *}[.21, .44]$ \\
\hline 6. Altruistic purpose & 6.27 & 0.65 & $.74^{* * * *}[.59, .89]$ & $.41^{* * *}[.29, .54]$ & $.44^{* * * *}[.31, .56]$ \\
\hline \multicolumn{6}{|l|}{ Study $3, N=247$} \\
\hline 1. Others-growth purpose orientation & 5.99 & 0.89 & - & & \\
\hline 2. Self-growth purpose orientation & 5.52 & 1.12 & $.54^{* * * *}[.40, .68]$ & - & \\
\hline 3. Career-focused purpose orientation & 5.54 & 1.23 & $.59^{* * * *}[.46, .72]$ & $.59^{* * * *}[.44, .73]$ & - \\
\hline 4. Awakening to purpose & 5.12 & 1.37 & $.37^{* * * *}[.21, .54]$ & $.39^{* * *}[.26, .52]$ & $.27^{* * *}[.13, .41]$ \\
\hline 5. Awareness of purpose & 5.54 & 1.34 & $.33^{* * *}[.15, .50]$ & $.20^{* * *}[.06, .34]$ & $.20^{* *}[.05, .35]$ \\
\hline 6. Altruistic purpose & 6.33 & 0.64 & $.58^{* * * *}[.44, .73]$ & $.16^{*}[0, .32]$ & $.36^{* * * *}[.19, .53]$ \\
\hline
\end{tabular}

Note. ${ }^{*} p<.05,{ }^{* *} p<.01,{ }^{* * *} p<.001$ 
12-item Purpose Orientation of Working Adults Scale with a sample of K-12 teachers. The 12 items included four others-growth purpose orientation items, four selfgrowth purpose orientation items, and four career-focused purpose orientation items and used the 1 (strongly disagree) to 7 (strongly agree) response scale. The purpose of Study 3 was to confirm factor structure with an independent sample of working adults and to further validate its items.

\section{Study 3 Results}

No missing data were observed on the individual items. The three-factor model with 12 items showed a good fit: $\chi^{2}(51, N=247)=119.38, p<0.001$, CFI $=0.950$, $\mathrm{TLI}=0.935$, RMSEA $=0.074,90 \%$ CI $[0.057,0.091]$, SRMR $=0.046$, thus confirming factor structure with a sample of teachers. Factor loadings on the hypothesized factors were significant and, as shown in Table 2, ranged from 0.79 to 0.90 .

As shown in Table 3, construct reliability estimates were 0.87 for others-growth, 0.87 for self-growth, and 0.88 for career-focused purpose orientation and were all above 0.70 . The AVE values were 0.63 for others-growth, 0.63 for self-growth, and 0.65 for career-focused purpose orientation, and were all greater than 0.50 but less than the corresponding CR values, thus, providing evidence of convergent validity. The ASV and MSV values were 0.35 and 0.32 for others-growth, 0.34 and 0.32 for self-growth, and 0.35 and 0.35 for career-focused purpose orientation and were all lower than their corresponding AVE values, thus providing evidence of discriminant validity (Table 3).

The combined model with the 12 items measuring specific purpose orientations and 14 items measuring sense of purpose, which consisted of six factors, showed a good model fit: $\chi^{2}(284, N=247)=498.36, p<0.001, \mathrm{CFI}=0.952, \mathrm{TLI}=0.945$, RMSEA $=0.055,90 \%$ CI [0.047, 0.063], SRMR $=0.051$. As shown in Table 4, all factors were positively correlated with each other. Correlations between the purpose orientation factors and the three factors of SOPS-2 ranged from 0.16 to 0.58 , providing evidence of criterion validity. Similar to results in Study 1 and Study 2, altruistic purpose correlated most strongly with others-growth purpose orientation. In contrast to results in Study 2, correlations in Study 3 were generally lower in their magnitude. Overall, both others-growth and career-focused purpose orientations had the highest correlations with altruistic purpose, whereas self-oriented purpose orientation was most strongly correlated with awakening to purpose.

Descriptive statistics is shown in Table 4. Tests of within-subject effects comparing strength of the three purpose orientation $\left(F(2,492)=29.37, p<0.001, \eta_{\text {partial }}^{2}=\right.$ $0.11)$ with simple contrasts showed that teachers reported much stronger othersgrowth purpose orientation $(M=5.99, S D=0.89)$ compared to self-growth purpose orientation $\left(M=5.52, S D=1.12, F(1,246)=50.51, p<0.001, \eta_{\text {partial }}^{2}=0.17\right)$ or career-focused purpose orientation $(M=5.54, S D=1.23, F(1,246)=43.00$, $\left.p<0.001, \eta_{\text {partial }}^{2}=0.15\right)$. However, no differences emerged in teachers' self-growth vs. career-focused purpose orientation $(F(1,246)=0.12, p=0.728)$. 
The longer the teachers have been teaching, the higher they reported their careerfocused purpose orientation $(r(245)=0.14, p=0.034)$. However, no differences in others-growth, self-growth, and career-focused purpose orientations were found based on teachers' grade level (elementary, middle, high school), the type of school (urban, suburban, rural), and whether this was their first career.

\section{Study 3 Discussion}

Results confirmed the three-factor structure with an independent sample of teachers, providing evidence of factorial validity. Results from CFA also suggested evidence of reliability, convergent validity, discriminant validity, and criterion validity. Nomological validity was also evidenced based on the examination of subscale scores in relation to teachers' characteristics.

\section{General Discussion}

The purpose of this study was to develop, refine, and validate a measure of specific purpose orientations for the use with adults in three studies. In Study 1, we developed items and pilot-tested them with a convenience sample of adults recruited through MTurk with the goal to empirically determine the number of factors and select best-performing items through exploratory factor analysis. Confirmatory factor analysis was then used in Studies 2 and 3 to test the factor-structure identified in Study 1 with two new independent samples. In Study 2, the selected items were refined and tested with a sample of intercollegiate coaches with the goal to confirm factor structure identified in Study 1 and further refine the scale by optimize its length. Finally, in Study 3, the final items were tested with an independent sample of K-12 teachers with the goal to confirm factor structure and to further validate the items for the use working adults. As a result, 12 items were identified as final to constitute the specific purpose orientations scale, designed to measure the dimensions of others-growth, self-growth, and career-focused purpose orientation. Psychometric properties of these items were further assessed in Studies 2 and 3, providing evidence of construct validity and reliability.

At the phase of item development and content validation, the items were assumed to focus on five dimensions of purpose orientation focusing on people's resolve to realize altruistic causes: engage in community-oriented activities; foster growth of other people; achieve personal growth; nurture personal virtues; and fulfill careerfocused aspirations. However, the results of parallel analysis and exploratory factor analysis in Study 1 suggested three distinct factors of purpose orientation. Specifically, the first two dimensions, which were initially hypothesized to be distinct, collapsed into a single factor, which was labeled others-growth purpose orientation. This dimension of purpose orientation is defined as actualizing one's purpose in life through engagement in activities that would enrich the lives of other people. This dimension of purpose reflects the beyond-the-self component of purpose that is central to the one of the most recognized definition of purpose which was 
proposed by Damon et al. (2003). The others-growth purpose orientation has also been suggested across multiple studies and groups of scholars who has focused their research efforts on examining purpose in adolescents, emerging adults, and adults (e.g., other-focused: Heng et al., 2017, 2020; prosocial orientation: Hill et al., 2010; altruistic orientation: Sharma et al., 2018; other-oriented: Summers \& Falco, 2020; social dedication: Wang et al., 2020). For example, in a study with Chinese college students, Wang et al. (2020) defined this dimension as contribution to others and the world.

Likewise, the two self-oriented dimensions collapsed into a single factor, which was labeled self-growth purpose orientation. This dimension of purpose orientation is defined as actualizing one's purpose in life through engaging in activities that make oneself a better person. Previous research has identified other forms of selforiented purpose orientations (e.g., self-focused: Heng et al., 2017, 2020; self-oriented: Sharma et al., 2017 and Summers \& Falco, 2020; self-strengthening: Wang et al., 2020). However, in the present study the self-oriented purpose is characterized by people's drive to purposefully engage in action that could positively transform the inner core of their own life, which according to humanistic philosophers is the key to bringing forth life's limitless strength to persevere amidst adversity (Ikeda, 2017).

Finally, the last dimension, which was labeled career-focused purpose orientation, is viewed as people's resolve to excel in their chosen profession and actualize their work-related potential. The presence of this purpose-oriented dimension has been suggested in previous studies. For example, Sharma et al. (2017) identified career purpose orientation as adolescents' desire to realize their career aspirations. While there is no direct equivalent dimension, career-focused purpose orientation is most closely aligned to the social recognition dimension that was derived with Chinese college students by Wang et al. (2020), defined as pursuit of others' recognition and respect. However, as recognized by Wang et al. (2020) differences exist between Chinese and Western cultures, suggesting that a sense of responsibility to the self is prioritized in Western culture over responsivity to the community, which is not so in Chinese culture. Similar to Bragger et al.'s (2021) emphasis on cultivating working adults' purpose as the means to promote both professional outcomes and personal wellbeing, the results of the present study have also shown that career-focused purpose orientation can be congruent with others-growth and self-growth purpose orientations.

These results on initially predicted dimensions to merge together into three factors (others-growth, self-growth, and career-focused purpose orientations) are consistent with Hill et al.'s (2010) assertion that people express their life's purpose through pursuing multiple but related life goals. Based on these results and previous theoretical perspectives (Damon et al., 2003; Hill et al., 2010), we can conclude that purpose orientation is the underlying intention behind people's long-term aspirations, which can be self-oriented, others-oriented, and domain specific (e.g., career, religion, education). The present study has focused on one domain of career since our focus was to support working adults in using this scale. In future, we can expand this scale to encompass other domains such as education to support students in reflecting upon their purpose orientations. The items measuring the self-growth 
purpose orientation are in accord with cross-cultural insights on the importance of assessing people's self-strengthening purpose orientation (Wang et al., 2020) and focus on their personal growth and inner-transformation (Ikeda, 2017). The items of others-growth purpose orientation are based upon Damon et al.'s (2003) definition of purpose as "a stable and generalized intention to accomplish something that is at once meaningful to the self and of consequence to world beyond the self" (p. 121). Accordingly, people's purpose can promote their personal sense of meaning and it can also contribute to others wellbeing. In the present study, "others" can refer to people's own family, friends, community, and world at large.

\section{Implications for Practice}

Having a valid and reliable instrument designed to measure purpose orientations such as others-growth, self-growth, and career-focused orientations is important for several reasons. First, the developed scale can potentially be used within counseling settings as a formative assessment tool to support working adults who are seeking a deeper purpose in life. It is likely to be effective as a tool that aids adults to reflect upon their life's purpose and gain insights into who they are and what they aspire to use their life for. Given the importance of cultivating sense of purpose among working adults to promote their professional outcomes and personal benefits (Bragger et al., 2021; Graça et al., 2021), using the career-focused purpose orientation dimension of this scale might support in helping working adults discuss the intersections between their work, personal growth, family, and larger purpose in life. The use of this scale in counseling sessions with working adults could further support counselors in promoting work-life balance through helping clients to reflect upon their life's priorities and purpose orientations.

The scale can further be used to evaluate the effectiveness of career counseling interventions that align with career constructivists focus on purpose as an engine that drives people's career and helps them to cope with difficult transitions (Savickas, 2012; Tiedeman \& Field, 1968). Such purpose-focused counseling practice might be especially meaningful during the current era of COVID-19 pandemic that we believe has exacerbated existential anxiety among working adults. Apart from counselors, management training can also benefit from using this scale to help organizational managers and leaders discuss the ways to help their employees connect the sense of purpose and meaningfulness at work with the larger purpose of their lives (Bragger et al., 2021).

\section{Limitations and Future Directions}

These results should be interpreted within the context of this study's limitations. First, this scale is validated for the use with working adults. Future research is needed on whether the scale can be used with other adult populations, such as college students. Second, the samples recruited in Studies 2 and 3 were obtained within the context of COVID-19. While there is no reason to believe that the factor structure would be different, the strength of each purpose orientation reported by 
coaches and teachers in Studies 2 and 3 might be different from before COVID-19. For example, purpose orientation of coaches and teachers might shift depending on whether they work in a face-to-face mode or online. A third limitation is the use of web-based surveys, which can result in coverage and non-response bias. Nevertheless, the use of web-based surveys has a number of advantages (e.g., cost) and is particularly helpful in the context of physical distancing. Overall, future studies should continue validating this scale.

\section{Conclusion}

In sum, the purpose of this study was to develop and validate a scale designed to measure purpose orientation among working adults. Results provided good evidence of construct validity and reliability, indicating that the items of the purpose orientations scale can be used to measure three distinct dimensions of life orientation (i.e., others-growth, self-growth, and career-focused). Overall, the items can be used with adults for research and as a tool for reflection on the nature of their life purpose to ultimately promote wellbeing in the working adult populations. The use of this scale in research can further contribute to continuing building research-based knowledge in the field of positive human functioning and wellness.

Acknowledgements We wish to acknowledge the support of Dr. Jennifer J. Enns for Study 3 data.

Author Contributions Mariya Yukhymenko-Lescroart: Conceptualization; Data curation; Methodology; Formal analysis; Investigation; Resources; Data curation; Writing —original draft; Writing—Review \& Editing; Visualization; Project administration.

Gitima Sharma: Conceptualization; Writing—original draft; Writing—Review \& Editing.

Data Availability The data, SPSS syntax, and Mplus syntax are available upon request from the author.

\section{Declarations}

Ethics approval All procedures performed in studies involving human participants were in accordance with the ethical standards of the institutional and/or national research committee and with the 1964 Helsinki declaration and its later amendments or comparable ethical standards.

Consent Informed consent was obtained from all individual participants included in the study.

Conflicts of interest There are no relevant financial or non-financial interests to disclose.

\section{References}

Bragger, J. D., Reeves, S., Toich, M. J., Kutcher, E., Lawlor, A., Knudsen, Q. E., \& Simonet, D. (2021). Meaningfulness as a predictor of work-family balance, enrichment, and conflict. Applied Research in Quality Life, 16, 1043-1071. https://doi.org/10.1007/s11482-019-09796-Z

Bronk, K. C., Hill, P. L., Lapsley, D. K., Talib, T. L., \& Finch, W. H. (2009). Purpose, hope, and life satisfaction in three age groups. The Journal of Positive Psychology, 4, 500-510. https://doi.org/10.1080/ 17439760903271439 
Buhrmester, M. D., Talaifar, S., \& Gosling, S. D. (2018). An evaluation of Amazon's Mechanical Turk, its rapid rise, and its effective use. Perspectives on Psychological Science, 13(2), 149-154. https:// doi.org/10.1177/1745691617706516

Burrow, A. L., \& Hill, P. L. (2011). Purpose as a form of identity capital for positive youth adjustment. Developmental Psychology, 47(4), 1196-1206. https://doi.org/10.1037/a0023818

Crumbaugh, J. C., \& Maholick, L. T. (1964). An experimental study in existentialism: The psychometric approach to Frankl's concept of noogenic neurosis. Journal of Clinical Psychology, 20, 589-596. https://doi.org/10.1002/1097-4679(196404)20:2\%3c200::AID-JCLP2270200203\% 3e3.0.CO;2-U

Dalton, J. C., and Crosby, P. C. (2010). When faith fails: Why nurturing purpose and meaning are so critical to student learning and development in college. Journal of College and Character, 11, 1-6. https://doi.org/10.2202/1940-1639.1720

Damon, W., Menon, J., \& Bronk, K. C. (2003). The development of purpose during adolescence. Applied Developmental Science, 7(3), 119-128. https://doi.org/10.1207/S1532480XADS0703_2

DeVellis, R. F. (2017). Scale development: Theory and Applications (4th ed.). Sage.

Frankl, V. E. (1984). Man's search for meaning (rev. ed.). Simon \& Schuster.

Goodreads (n.d.). Purpose of life quotes. https://www.goodreads.com/quotes/tag/purpose-of-life. Accessed 24 Aug 2021.

Graça, M., Pais, L., Mónico, L., Dos Santos, N. R., Ferraro, T., \& Berger, R. (2021). Decent work and work engagement: A profile study with academic personnel. Applied Research Quality Life, 16, 917-939. https://doi.org/10.1007/s11482-019-09780-7

Hair, J. F., Jr., Black, W. C., Babin, B. J., \& Anderson, R. E. (2019). Multivariate data analysis (8th ed.). Cengage.

Heng, M. A., Blau, I., Fulmer, G. W., Bi, X., \& Pereira, A. (2017). Adolescents finding purpose: Comparing purpose and life satisfaction in the context of Singaporean and Israeli moral education. Journal of Moral Education, 46(3), 308-322. https://doi.org/10.1080/03057240.2017.1345724

Heng, M. A., Fulmer, G. W., \& Blau, I. (2020). Youth purpose, meaning in life, social support and life satisfaction among adolescents in Singapore and Israel. Journal of Educational Change, 21, 299322. https://doi.org/10.1007/s10833-020-09381-4

Hill, P. L., Burrow, A. L., Brandenberger, J. W., Lapsley, D. K., \& Quaranto, J. C. (2010). Collegiate purpose orientations and well-being in adulthood. Journal of Applied Developmental Psychology, 31, 173-179. https://doi.org/10.1016/j.appdev.2009.12.001

Hill, P. L., Sin, N. L., Turiano, N. A., Burrow, A. L., \& Almeida, D. M. (2018). Sense of purpose moderates the associations between daily stressors and daily well-being. Annals of Behavioral Medicine, 52, 724-729. https://doi.org/10.1093/abm/kax039

Ikeda, D. (2017). The wisdom for creating happiness and peace. World Tribune Press.

Kang, Y., Strecher, V. J., Kim, E., \& Falk, E. B. (2019). Purpose in life and conflict-related neural responses during health decision-making. Health Psychology, 38(6), 545-552. https://doi.org/10. 1037/hea0000729

Kim, E. S., Shiba, K., Boehm, J. K., \& Kubzansky, L. D. (2020). Sense of purpose in life and five health behaviors in older adults. Preventive Medicine, 139, 106172. https://doi.org/10.1016/j.ypmed.2020. 106172

McKnight, P. E., \& Kashdan, T. B. (2009). Purpose in life as a system that creates and sustains health and well-being: An integrative, testable theory. Review of General Psychology, 13, 242-251. https://doi. org/10.1037/a0017152

Muthén, L. K., \& Muthén, B. O. (2012-2021). Mplus (Version 8.6) [computer software]. Muthén \& Muthén.

O'Connor, B. P. (2000). SPSS and SAS programs for determining the number of components using parallel analysis and Velicer's MAP test. Behavior Research Methods, Instruments, \& Computers, 32, 396-402. https://doi.org/10.3758/BF03200807

Roberts, B. W. and Robbins, R. W. (2000). Broad dispositions, broad aspirations: The intersection of personality traits and major life goals. Personality and Social Psychology Bulletin, 26, 1284-1296. https://doi.org/10.1177/0146167200262009

Ryff, C. D. (1989). Happiness is everything, or is it? Explorations on the meaning of psychological wellbeing. Journal of Personality and Social Psychology, 57, 1069-1081. https://doi.org/10.1037//00223514.57.6.1069

Savickas, M. L. (2012). Life design: A paradigm for career intervention in the 21st century. Journal of Counseling and Development, 90, 13-19. https://doi.org/10.1111/j.1556-6676.2012.00002.x 
Sharma, G., \& de Alba, E. (2018). Sense of purpose among female students belonging to minority ethnic and Buddhist backgrounds. Journal of College and Character, 19, 137-151. https://doi.org/10.1080/ 2195487X.2018.1445644

Sharma, G., Kim, J., \& Bernal, K. (2021). The Relationship between the High School Sophomores' Purpose Orientations and their Post-Secondary Education Completion a Decade Later. Professional School Counseling Journal, 25(1), 1-10. https://doi.org/10.1177/2156759X20981051

Sharma, G., Kim, J., \& Bryan, J. A. (2017). The effects of purpose orientations on high school graduates' college application decisions. Journal of College Access, 3, 98-117.

Sharma, G., Yukhymenko-Lescroart, M. A., \& Kang, Z. (2018). Sense of Purpose Scale: Development and initial validation. Applied Developmental Science, 28(3), 188-199. https://doi.org/10.1080/ 10888691.2016 .1262262

Sharma, G., \& Yukhymenko-Lescroart, M. A. (2018). The Relationship between college students' sense of purpose and degree commitment. Journal of College Student and Development, 59, 486-491. https://doi.org/10.1353/csd.2018.0045

Sharma, G., \& Yukhymenko-Lescroart, M. A. (2019). Validation of the Revised Sense of Purpose Scale (SOPS-2) with emerging adults. Journal of Character Education, 15, 39-52.

Summers, J. J., \& Falco, L. D. (2020). The development and validation of a new measure of adolescent purpose. The Journal of Experimental Education, 88(1), 47-71. https://doi.org/10.1080/00220973. 2019.1575178

Tiedeman, D. V., \& Field, F. L. (1968). Measurement for guidance. In D. K. Whitla (Ed.). Handbook for measurement and assessment in behavioral sciences (pp. 419-435). Reading, MA: Addison-Wesley.

Wang, T., You, X. Q., \& Huang, X. T. (2020). Chinese life purpose orientation questionnaire: assessing purpose orientations among Chinese college students. Applied Developmental Science. Advanced online publication. https://doi.org/10.1080/10888691.2020.1815535

Windsor, T. D., Curtis, R. G., \& Luszcz, M. A. (2015). Sense of purpose as a psychological resource for aging well. Developmental Psychology, 51(7), 975-986. https://doi.org/10.1037/dev0000023

Yeager, D. S., \& Bundick, M. J. (2009). The role of purposeful work goals in promoting meaning in life and in schoolwork during adolescence. Journal of Adolescent Research, 24(4), 423-452. https://doi. org/10.1177/0743558409336749

Yukhymenko-Lescroart, M. A., \& Sharma, G. (2020a). Examining the factor structure of the revised sense of purpose scale (SOPS-2) with adults. Applied Research in Quality of Life, 15, 203-1222. https://doi.org/10.1007/s11482-019-09729-w

Yukhymenko-Lescroart, M. A., \& Sharma, G. (2020b). Passion for work and well-being of working adults. Journal of Career Development. Advanced online publication. https://doi.org/10.1177/08948 45320946398

Publisher's Note Springer Nature remains neutral with regard to jurisdictional claims in published maps and institutional affiliations. 